\title{
O CASAMENTO DAS PESSOAS COM DEFICIÊNCIA MENTAL NO BRASIL: IDENTIDADE, CULTURA E FAMÍLIA.
}

\section{Iara Antunes de Souza ${ }^{1}$}

RESUMO: As pessoas com deficiência mental podem exercer, por si só, os atos da vida civil de natureza existencial, incluindo o direito ao casamento, baseado nas normas do Estatuto da Pessoa com Deficiência, baseado no tratado internacional de Direitos Humanos das pessoas com deficiência - carta de Nova Iorque - aprovado com status de norma constitucional. O tratado determinou a incorporação junto aos ordenamentos jurídicos internos dos países signatários de conquistas culturais e identitárias acerca dos Direitos das pessoas com deficiência. Assim, apresenta-se discussão sobre o tema na vertente jurídico-dogmática, com raciocínio hipotético-dedutivo, e investigação jurídico-descritivo e jurídico-interpretativo.

PALAVRAS-CHAVE: Pessoa com Deficiência; Casamento; Direitos identitários; Direito das Famílias; Estatuto da Pessoa com Deficiência.

\section{MARRIAGE OF PEOPLE WITH MENTAL DISABILITY IN BRAZIL: IDENTITY, CULTURE AND FAMILY.}

ABSTRACT: People with mental disabilities can exercise byself the existential's acts of civil life, including the right to marriage, based on the rules of the brazilian's Statute of the Person with Disabilities, based on the persons with disabilities's international human rights treaty New York's Charter - approved with status of constitutional norm. The treaty determined the incorporation in the internal legal systems of the signatory countries of cultural and identity achievements about the Rights of persons with disabilities. Therefore, present a discussion about it on the legal-dogmatic side, with hypothetical-deductive reasoning, and legaldescriptive and legal-interpretative research.

KEY WORDS: Person with mental disabilities; Marriage; Identity achievements; Family law; Statute of the Person with Disabilities.

\section{INTRODUÇÃO}

No dia 02 de março de 2016 foi publicada no site do IBDFAM - Instituto Brasileiro de Direito das Famílias - notícia intitulada "Cartório paulista sai na frente e realiza casamento inédito de pessoa com deficiência, depois da Lei Brasileira de Inclusão". Trata-se do casamento de R. A. O. L., de 44 anos de idade, e J. F. D., de 53 anos de idade, casal com 19 anos de convivência e um filho de 17 anos.

\footnotetext{
${ }^{1}$ Doutora e Mestra em Direito Privado pela PUC Minas. Especialista em Direito Processual e Direito Civil. Professora da graduação e da pós-graduação do Departamento de Direito da Universidade Federal de Ouro Preto - UFOP. Pesquisadora do Novos Direitos Privados e vulnerabilidades e do Centro de Estudos em Biodireito CEBID 
A união não havia sido oficializada antes, pois, no Direito brasileiro, pessoas como R. A. O. L., com deficiência mental ou intelectual, eram consideradas absolutamente incapazes e, assim, interditadas de forma absoluta, o que retirava delas a capacidade de exercer, por si só, os atos da vida civil, incluindo os atos existenciais, como casamento.

Fala-se no passado, pois, desde janeiro de 2016 o Direito brasileiro conta com um microssistema jurídico de proteção e promoção da pessoa com Deficiência, diante da entrada em vigor da Lei n. 13.146 (BRASIL, 2015a), que "Institui a Lei Brasileira de Inclusão da Pessoa com Deficiência" que é conhecida como Estatuto da Pessoa com Deficiência - EPD. A legislação trata do direito à igualdade e não discriminação; direitos fundamentais como saúde, acessibilidade e educação; direitos sociais como o trabalho, previdência e moradia; por exemplo.

A lei efetiva a Convenção Internacional sobre os Direitos das Pessoas com Deficiência - Carta de Nova Iorque, da qual o Brasil é signatário, e que se incorporou ao Direito brasileiro por meio do Decreto n. 6.949, de 25 de agosto de 2009 (BRASIL, 2009), e, considerando que sua aprovação se deu nos termos do disposto no $\S 3^{\circ}$ do $\operatorname{artigo} 5^{\circ}$ da Constituição da República de 1988 (BRASIL, 1988), a dita convenção tem status de norma constitucional. O que se percebe, portanto, é que os Direitos das pessoas com deficiência são normas fundamentais, constitucionalmente asseguradas desde 2009. O que o estatuto fez foi, ao ser introduzido no ordenamento legal, buscar a mudança da cultura de direitos relativos às pessoas com deficiência.

Interessa-se, em particular, investigar as alterações envolvendo a teoria das incapacidades civis e suas consequências nos direitos existenciais das pessoas com deficiência, em especial as alterações que essa nova ordem jurídica trouxe para o Direito das Famílias, seja junto à curatela, seja junto ao casamento.

Afinal, considerando a situação de vida concreta apresentada na notícia em epígrafe, demonstra falta de correspondência entre os contextos de vida real e a normatividade passada e, por vezes, vigente, de forma que se impõe reflexão sobre os movimentos e os processos culturais e normativos relacionados aos direitos identitários e de família.

Para tanto, apresenta-se pesquisa na vertente jurídico-dogmática, com raciocínio hipotético-dedutivo, e investigação jurídico-descritivo e jurídico-interpretativo (GUSTIN; DIAS, 2013, p.20-28), eis que se trabalha com a compreensão normativa de vários ramos do Direito, conhecimentos prévios e da pesquisa; bem como há descrição de situação jurídica e sua decomposição para fins de análises de suas circunstâncias e vicissitudes. 
Logo, discute-se a incapacidade, o conceito de deficiência e a curatela, chegando-se ao casamento da pessoa com deficiência, numa visão identitária, cultural e de família.

\section{DA INCAPACIDADE, CONCEITO DE DEFICIÊNCIA E CURATELA}

Apresenta-se a evolução da construção da ideia de (in)capacidade civil no contexto do Direito brasileiro, hodiernamente com base nas questões atinentes ao conceito de deficiência, chegando à curatela.

\subsection{Da (in) capacidade civil no Direito brasileiro a partir da acepção do conceito de deficiência}

O Código Civil brasileiro reconhece a condição de pessoa e atribui personalidade jurídica, seja em seu aspecto subjetivo, seja em seu aspecto objetivo ${ }^{2}$, a todas as pessoas que nascem com vida. A personalidade subjetiva é ligada à capacidade de direito ou de gozo, conforme ensina Francisco Amaral (2006, p.248). Trata-se da aptidão para titularizar e exercer os direitos na ordem civil. Ao lado dessa está a capacidade de fato ou de exercício que representa o "[...] poder efetivo que nos capacita para a prática plena de atos da vida civil." (FIUZA, 2010, p. 129), de exercê-los, por si só.

Os conceitos de personalidade e autonomia são essenciais para a determinação da capacidade jurídica das pessoas, segundo Brunello Souza Stancioli (2004, p. 44). A autonomia privada é um princípio jurídico que concede poderes de atuação à pessoa, sua autodeterminação (SA; NAVES, 2015, p.41-42). O elemento essencial para a manifestação da autonomia do sujeito de direito dotado de personalidade jurídica, desde que capaz de estabelecer diferença, distinguir, fazer apreciação, segundo os autores, segundo Maria de Fátima Freire de Sá e Bruno Torquato de Oliveira Naves (2015, p.108) é o discernimento. Parece, entretanto, que o atual ordenamento, alterado pelo Estatuto da Pessoa com

\footnotetext{
* Lattes: http://lattes.cnpq.br/0058010358863049. E-mail: iara@ufop.edu.br

${ }^{2} \mathrm{Na}$ acepção subjetiva a personalidade confunde-se com a capacidade de direito ou de gozo, que é atribuída a todos que nascem com vida, nos termos dos artigos $1^{\circ}$ e $2^{\circ}$ do Código Civil (BRASIL, 2002) e às pessoas jurídicas. Trata-se, portanto, de atributo jurídico, centro de imputação normativa. Sob a perspectiva objetiva, personalidade é um conjunto de atributos humanos que merecem proteção jurídica, ou seja, é o objeto do Direito. Concebe-se aqui o direito de personalidade, que é o direito afeto aos atributos intrínsecos da personalidade humana (FIUZA, 2010, p.171). 
Deficiência, colocar a possibilidade de expressão de vontade como requisito para a consideração da capacidade.

Logo, o ordenamento jurídico parte da regra de que as pessoas são civilmente capazes, ou seja, capazes, tecnicamente, de, com aptidão, se autodeterminar, reconhecer o sentido das informações e tomar suas decisões considerando os prós e os contras. Seria aquela pessoa que exerce, eficazmente, sua autonomia privada (SOUZA, 2018). Atualmente, a pessoa que pode exprimir sua vontade.

Contudo, na prática, pode ser que a pessoa não tenha como exprimir vontade. E isso pode ocorrer por várias razões atreladas, em especial, à saúde mental. A tradição da incapacidade da pessoa no ordenamento jurídico brasileiro é seu tratamento como exceção, em razão da idade ou em razão da saúde mental. Importa ao estudo a incapacidade em razão da saúde mental, que fora, em especial no Código Civil de $1916^{3}$ e na versão originária do Código Civil de 2002, atrelada à loucura, à alienação, ao transtorno e à doença mental, baseada na cultura médica ${ }^{4}$.

Contudo, o tratamento dado as questões de saúde mental, preponderantemente quando se trabalha com a deficiência, deixou de ser medicalizada e patologizada, passando a ser social, de forma que sua avaliação e reconhecimento nos campos bio-médico-jurídico passaram a demandar uma avaliação psicossocial e multidisciplinar. Não basta um laudo médico com CID para a categorização da deficiência. Nem mesmo a previsão categorizada, como disposto no artigo $4^{05}$ do Decreto n. 3.298/99, é admitida. Nesse sentido, Romário Faria

\footnotetext{
${ }^{3}$ Art. 5. São absolutamente incapazes de exercer pessoalmente os atos da vida civil:

I. Os menores de dezesseis anos.

II. Os loucos de todo o gênero.

III. Os surdos-mudos, que não puderem exprimir a sua vontade.

IV. Os ausentes, declarados tais por ato do juiz. (BRASIL, 1916, grifos nossos).

${ }^{4}$ Sobre o tema, sugere-se a leitura da primeira parte do livro de Iara Antunes de Souza (2016), sobre a evolução histórica e o tratamento médico da saúde mental.

${ }^{5}$ Art. 4o É considerada pessoa portadora de deficiência a que se enquadra nas seguintes categorias:[...]

I - deficiência física - alteração completa ou parcial de um ou mais segmentos do corpo humano, acarretando o comprometimento da função física, apresentando-se sob a forma de paraplegia, paraparesia, monoplegia, monoparesia, tetraplegia, tetraparesia, triplegia, triparesia, hemiplegia, hemiparesia, ostomia, amputação ou ausência de membro, paralisia cerebral, nanismo, membros com deformidade congênita ou adquirida, exceto as deformidades estéticas e as que não produzam dificuldades para o desempenho de funções; (Redação dada pelo Decreto $\mathrm{n}^{\circ} 5.296$, de 2004)

II - deficiência auditiva - perda bilateral, parcial ou total, de quarenta e um decibéis (dB) ou mais, aferida por audiograma nas freqüências de 500HZ, $1.000 \mathrm{HZ}, 2.000 \mathrm{~Hz}$ e $3.000 \mathrm{~Hz}$; (Redação dada pelo Decreto $\mathrm{n}^{\circ} 5.296$, de 2004)

III - deficiência visual - cegueira, na qual a acuidade visual é igual ou menor que 0,05 no melhor olho, com a melhor correção óptica; a baixa visão, que significa acuidade visual entre 0,3 e 0,05 no melhor olho, com a melhor correção óptica; os casos nos quais a somatória da medida do campo visual em ambos os olhos for igual ou menor que 60o; ou a ocorrência simultânea de quaisquer das condições anteriores; (Redação dada pelo
} Decreto $\mathrm{n}^{\circ}$ 5.296, de 2004) 
(2015) relator do Projeto de Lei que deu origem ao Estatuto da Pessoa com Deficiência, ao tratar do conceito de deficiência, que a nova legislação assumiria, assim, se posicionou:

\begin{abstract}
Acolhemos a sugestão da Câmara dos Deputados. Não há uma deficiência intrínseca. A deficiência decorre de uma característica atípica da pessoa em interação com barreiras de diversas categorias existentes na sociedade. Por isso, $\underline{\mathbf{0}}$ conceito de deficiência está em permanente evolucão, uma vez que cada vez mais se estudam e se descobrem condições raras de indivíduos que os impedem de exercer plenamente suas potencialidades, dada a existência dessas barreiras mencionadas.

$[\ldots]$

No art. 20, o SCD explicita o conceito de pessoa com deficiência: "aquela que tem impedimentos de longo prazo de natureza física, mental, intelectual ou sensorial, os quais, em interação com uma ou mais barreiras, podem obstruir sua participação plena e efetiva na sociedade em igualdade de condições com as demais pessoas.". Nessa definição, deparamo-nos com uma primeira e relevante distinção entre as proposições: enquanto o PLS estatuía detalhadamente o que era deficiência, especificando cada uma de suas tipologias e parâmetros, o SCD preferiu encampar a diretriz da Convenção e remeter a identificação da deficiência para uma avaliação biopsicossocial a cargo de equipe multidisciplinar.
\end{abstract}

Logo, o que o Estatuto da Pessoa com Deficiência traz é a despatologização da deficiência e, consequentemente, da incapacidade. Ora, a doença não é causa necessária de deficiência e nem aquela e nem essa, por si só, são causa de incapacidade. Seu grande avanço foi, de fato, retirar de uma vez por todas do ordenamento jurídico a possibilidade de ligar o transtorno e a deficiência mental, como critério, por si só, de incapacidade e garantir o exercício da capacidade na maior medida (SOUZA, 2018) de possibilidade de expressão de vontade.

Logo, sua verificação não se dá por médico isoladamente ou por equipe médica, mas sim por equipe multidisciplinar. Nesse sentido:

\begin{abstract}
A CDPD é o primeiro tratado de consenso universal que concretamente especifica os direitos das pessoas com deficiência pelo viés dos direitos humanos, adotando um modelo social de deficiência que importa em um giro transcendente na sua condição. Por esse modelo, a deficiência não pode se justificar pelas limitações pessoais decorrentes de uma patologia. Redireciona-se o problema para o cenário social, que gera entraves, exclui e discrimina, sendo necessária uma estratégia social que
\end{abstract}

IV - deficiência mental - funcionamento intelectual significativamente inferior à média, com manifestação antes dos dezoito anos e limitações associadas a duas ou mais áreas de habilidades adaptativas, tais como:

a) comunicação;

b) cuidado pessoal;

c) habilidades sociais;

d) utilização dos recursos da comunidade; (Redação dada pelo Decreto no 5.296, de 2004)

e) saúde e segurança;

f) habilidades acadêmicas;

g) lazer; e

h) trabalho;

V - deficiência múltipla - associação de duas ou mais deficiências. 
remova o pleno desenvolvimento da pessoa com deficiência. O objetivo da CDPD é o de permutar o atual modelo médico - que deseja reabilitar a pessoa anormal para se adequar à sociedade -, por um modelo social de direito humanos, cujo desiderato é o de reabilitar a sociedade para eliminar os muros de exclusão comunitária. A igualdade no exercício da capacidade jurídica requer o direito à uma educação inclusiva, a vida

independente e a possibilidade de ser inserido em comunidade (ROSENVALD, 2015).

O objetivo humanista da CDPD consagra inovadora visão jurídica a respeito da pessoa com deficiência. Nesse modelo, a deficiência não pode se justificar pelas limitações pessoais decorrentes de uma patologia. A ideia fulcral parece ser a de substituir o chamado "modelo médico" - que busca desenfreadamente reabilitar a pessoa anormal para se adequar à sociedade -, por um modelo "social humanitário" - que tem por missão reabilitar a sociedade para eliminar os entraves e os muros de exclusão, garantindo ao deficiente uma vida independente e a possibilidade de ser inserido em comunidade (RIBEIRO, 2015).

A capacidade é a regra, sempre foi, e agora não há como defender posição diferente diante do exposto no artigo $6^{\circ 6}$ do Estatuto da Pessoa com Deficiência, nem mesmo diante da presença de uma deficiência diagnosticada por uma equipe multidisciplinar. Este artigo é completado pelo artigo 84 do mesmo Estatuto que prevê em seu caput: “Art. 84. A pessoa com deficiência tem assegurado o direito ao exercício de sua capacidade legal em igualdade de condições com as demais pessoas.” (BRASIL, 2015a). Essas normas corroboram os princípios da Carta de Nova Iorque, em especial o previsto no artigo 12, 2: "2. Os Estados Partes reconhecerão que as pessoas com deficiência gozam de capacidade legal em igualdade de condições com as demais pessoas em todos os aspectos da vida.” (BRASIL, 2009).

Avança-se mais. Em que pese as modificações na teoria da incapacidades terem sido perpetradas pelo Estatuto da Pessoa com Deficiência, a incapacidade civil, na prática, diante da reforma e dos anseios já apresentados pelos estudiosos do direitos anteriores a ela, como Cristiano Chaves de Farias e Nelson Rosenvald (2009; 2012) e Maria de Fátima Freire de Sá e Diogo Luna Moureira (2011), não se vincula sequer à deficiência. A previsão atual do Código Civil de 2002 é:

\footnotetext{
${ }^{6}$ Art. $6^{\circ}$ A deficiência não afeta a plena capacidade civil da pessoa, inclusive para:

I - casar-se e constituir união estável;

II - exercer direitos sexuais e reprodutivos;

III - exercer o direito de decidir sobre o número de filhos e de ter acesso a informações adequadas sobre reprodução e planejamento familiar;

IV - conservar sua fertilidade, sendo vedada a esterilização compulsória;

$\mathrm{V}$ - exercer o direito à família e à convivência familiar e comunitária; e

VI - exercer o direito à guarda, à tutela, à curatela e à adoção, como adotante ou adotando, em igualdade de oportunidades com as demais pessoas. (BRASIL, 2015a). 


\begin{abstract}
Art. 3o São absolutamente incapazes de exercer pessoalmente os atos da vida civil os menores de 16 (dezesseis) anos. $\quad$ (Redação dada pela Lei n ${ }^{\circ} 13.146$, de 2015) I - (Revogado); $\quad$ (Redação dada pela Lei n n $^{\circ} 13.146$, de 2015) II - (Revogado); $\quad$ (Redação dada pela Lei no 13.146 , de 2015) III - (Revogado). (Redação dada pela Lei n ${ }^{\circ} 13.146$, de 2015)

Art. 4o São incapazes, relativamente a certos atos ou à maneira de os exercer: (Redação dada pela Lei $\mathrm{n}^{\circ} 13.146$, de 2015)

I - os maiores de dezesseis e menores de dezoito anos;

II - os ébrios habituais e os viciados em tóxico;

13.146, de 2015)

III - aqueles que, por causa transitória ou permanente, não puderem exprimir sua vontade; (Redação dada pela Lei n ${ }^{\circ} 13.146$, de 2015)

IV - os pródigos.

Parágrafo único. A capacidade dos indígenas será regulada por legislação especial. (Redação dada pela Lei n ${ }^{\circ} 13.146$, de 2015). (BRASIL, 2002, grifos nossos).
\end{abstract}

Da leitura do artigos $4^{\circ}$ e $5^{\circ}$ do Código Civil de 2002, infere-se que não há causas de saúde mental para fins de incapacidade absoluta e que, quanto à incapacidade relativa, substitui-se a ideia de falta de discernimento/competência para o exercício dos atos da vida civil, para o critério de impossibilidade de expressão de vontade, que pode ou não estar atrelado a uma doença ou a uma deficiência. Logo, afirma-se, pode existir mesmo na ausência de uma doença ou deficiência. A definição da incapacidade, segundo ditames do Estatuto da Pessoa com Deficiência e do Código de Processo Civil de 2015, é competência de uma equipe multidisciplinar, assemelhando-se, portanto à política pública brasileira de tratamento de saúde mental (SOUZA, 2018). A esta equipe caberá muito mais do que o diagnóstico de uma doença mental ou da verificação de uma deficiência. Cabe a ela sim e primordialmente avaliar se, excepcionalmente, a doença, a deficiência ou qualquer outro fato externo ou interno afeta a autodeterminação da pessoa, ou seja, afeta seu discernimento, a sua possibilidade de expressão de vontade para exercer os atos da vida civil.

O papel da equipe multidisciplinar e sua importância para o reconhecimento da incapacidade civil é relevante e já reconhecido pelo judiciário. De fato, a prova pericial juntada ao processo oriunda dos laudos da equipe multidisciplinar são o que, de fato, determina ou não a capacidade da pessoa. O juiz, apesar de não se vincular ao lado, não tem competência técnica para determinar ou não a incapacidade diante da audiência de entrevista de um curatelando (SOUZA, 2018). De fato, nesse sentido, decidiu o Tribunal de Justiça do Estado de Minas Gerais: 
Nesse espeque, ao contrário dos argumentos apresentados pelo Representante do Ministério Público de que o interditando demonstra capacidade para reger sua própria pessoa e os bens que porventura possua, considero que o laudo pericial aponta para conclusão em sentido contrário, conforme se denota da resposta aos quesitos transcritos alhures.

Afirma o douto Magistrado que, em interrogatório judicial, o interditando detinha condições de exprimir de maneira clara e lúcida seus pensamentos e vontades, o que evidenciaria que possui plena capacidade para gerir sua pessoa e seus bens. Destaca, ainda, que "o interditando não possui doença mental, mas apenas problemas de saúde que não podem ser considerados como fator impeditivo do requerido em reger sua própria pessoa e administrar seus bens".

A meu ver, contudo, tal constatação momentânea não é capaz de afastar o resultado da prova pericial, feita por profissional médico que detém conhecimento técnico para aferir em que medida a doença do paciente interfere nos atos da vida civil.

Com efeito, ainda que a decisão do MM. Magistrado não esteja adstrita ao laudo pericial, certo é que, em demandas desse jaez, a perícia médica oferece relevantes subsídios à formação do convencimento do julgador, na medida em que definirá "se existe causa incapacitante, e, caso positivo, em que grau de extensão compromete o exercício dos atos da vida civil (...)" (Dias, Maria Berenice; in Manual de Direito das Famílias, São Paulo, RT, 2011, p. 624).

Desse modo, em virtude dos pareceres mencionados, entendo que no caso vertente a interdição se revela como medida apropriada[...]. (MINAS GERAIS, 2017).

Se a capacidade é a regra, a incapacidade deve ser provada quando existir e nos limites em que existir.

\subsection{Da curatela}

Se for reconhecida a ausência ou diminuição da possibilidade de expressão de vontade, o parágrafo primeiro do artigo 84 do Estatuto da Pessoa com Deficiência traz a seguinte previsão: “ $\$ 1^{\circ}$ Quando necessário, a pessoa com deficiência será submetida à curatela, conforme a lei." A lei no caso, entende-se, é o Código Civil, que reconhece as hipóteses de incapacidade civil e o Código de Processo Civil que instrumentaliza as medidas de proteção à pessoa sem possibilidade de expressão de vontade, que aqui se trata, em razão da deficiência.

Por isso, a norma jurídica não deve trazer determinação expressa das hipóteses de incapacidade absoluta ou relativa. Esse seria esse um munus a ser exercido pela equipe multidisciplinar na análise acerca da inexistência de possiblidade de expressão de vontade total ou parcial para todos ou certos atos da vida civil.

E essa conclusão é relevante para fins de aplicabilidade da teoria das incapacidades na prática, eis que a função de proteção e a medida de cuidado são apostas pelo sistema jurídico com o fito de promover e proteger os direitos das pessoas que não está 
impossibilitada de expressar sua vontade e é graduada de acordo com o reconhecimento do grau da dirá impossibilidade, afastando, de todo modo, a ideia de incapacidade absoluta automática. Se houver o reconhecimento da impossibilidade de manifestação de vontade de forma parcial, deve ocorrer apenas a assistência para a realização dos atos. Contudo, caso haja o reconhecimento de ausência total de possibilidade de manifestação de vontade, ainda que para um ato, a representação será necessária. Sobre a representação no atual sistema:

\begin{abstract}
De acordo com o que o Código Civil prevê hoje, após as modificações realizadas pelo Estatuto da Pessoa com Deficiência, pensa-se inicialmente que não se poderia ter a figura do representante, pois não existem hipóteses previstas de incapacidade absoluta. Entretanto, considerando as críticas colacionadas e que a definição de existência ou não de discernimento e em que grau isso se dá não é uma função do Direito, mas sim da equipe multidisciplinar, é que se justifica o fato de se defender que, ainda que não exista a previsão de incapacidade absoluta, a representação será possível quando a equipe multidisciplinar concluir que a pessoa não tem discernimento para sozinha exercer o ato e mais, não puder ser ajudada para a consecução desse desiderato, o que entende excepcional, mas possível (SOUZA, 2018, p.208).
\end{abstract}

E ainda, para que, de fato, tal sistema seja conformado é essencial que o curador crie ou recrie a vontade do curatelado, junto ao à assistência e à representação, de acordo com sua biografia pessoal, familiar e social; pois percebe-se que, segundo os ditames da Carta de Nova Iorque, as medidas de cuidado e de apoio não devem ser substitutivas de vontade.

A posição acima esposada é concebida como nova epistemologia acerca da questão da representação e da assistência quando se trata de incapacidade reconhecida multidisciplinarmente, no contexto da teoria das incapacidades atual. Trata-se de uma reviravolta na cultura social e jurídica para fins de garantia dos Direitos identitários da pessoa com deficiência junto ao Direito das Famílias.

Especificamente sobre a curatela, percebe-se que o Estatuto da Pessoa com Deficiência não faz referência ao instituto da interdição, tratando, apenas, da curatela, tendo, inclusive, alterado dispositivos do Código Civil para substituir as expressões interdição por curatela $^{7}$. Surge então, a ideia de que a interdição foi excluída do ordenamento jurídico brasileiro, por força do escopo da Carta de Nova Iorque, concretizada no Estatuto da pessoa com Deficiência. Nesse sentido, segundo Paulo Lôbo deve prevalecer a norma do Estatuto da Pessoa com Deficiência, em que pese as disposições do novo Código de Processo Civil, ou seja, a interdição não existe mais:

${ }^{7} 1.768$ do Código Civil: “Art. 1.768. A interdição deve ser promovida: (Vide Lei n. 13.105, de 2015) Art. 1.768. O processo que define os termos da curatela deve ser promovido: (Redação dada pela Lei n. 13.146, de 2015) [...].” (BRASIL, 2002). 
As regras do novo CPC deverão ser interpretadas em conformidade com as da Convenção sobre os Direitos da Pessoa com Deficiência, pois esta tem força normativa superior àquele, relativamente à curatela especial, como medida protetiva e temporária, não sendo cabível a interpretação que retome o modelo superado de interdição, apesar da terminologia inadequada utilizada pela lei processual (LÔBO, 2015).

Contudo, acredita-se que a interdição é a medida jurídica e judicial cabível para que se comprove em juízo a impossibilidade de expressão de vontade e atribuição de curador para representar/assistir a pessoa (SOUZA, 2016):

Logo, não obstante as alterações do Estatuto da Pessoa com Deficiência. Entretanto, sua aplicação prática de outrora deve ser alterada e não pode ser usada mais como meio de segregação e afastamento indiscriminado da capacidade da pessoa, chegando a provocar sua morte civil. O instituto agora é promocional. A interdição serve como meio processual de comprovação da situação excepcional de ausência de discernimento, total ou parcial.

Ademais, é preciso ter em mente que as alterações feitas pelo Estatuto da Pessoa com Deficiência no Código Civil não atingiram o Código de Processo Civil de 1973 (BRASIL, 1973) e muito menos o Código de Processo Civil de 2015 (BRASIL, 2015b). E se tem uma antinomia legislativa. (SOUZA, 2018, p. 209).

Afinal, a questão problemática não é a interdição per si, mas a forma como ela sempre fora aplicada para trazer a incapacidade total da pessoa, sem considerar sua individualidade e a promoção de sua identidade pessoal, o que é escopo da Carta de Nova Iorque. Logo, a interdição e a curatela têm como escopo, no atual cenário jurídico a promoção da pessoa da capacidade da pessoa com deficiência e a aplicação da curatela como medida de cuidado. A interdição é o meio processual e a curatela o meio material de propiciar cuidado à pessoa que se demonstra vulnerável quanto à possibilidade de manifestação de vontade para os atos da vida civil. Por isso, conclui-se como Romário Faria (2015):

Na Antiguidade, o padrão social era a eliminação da pessoa com deficiência, com base na ideia de uma suposta inutilidade e inferioridade, inclusive por infanticídio e aborto. No Brasil Colônia, optava-se pelo confinamento dessas pessoas, fosse na família, em instituições ou mesmo em prisões. Com a Revolução Industrial, a deterioração das condições de trabalho fez surgir um cenário propicio ao aparecimento de doenças e acidentes, levando legiões de operários a adquirir deficiências. Surge, então, a abordagem medico-terapêutica da deficiência, encarada como algo a ser curado de sorte a reintegrar a pessoa a sociedade e a reabilita-la ao mercado de trabalho. Com o advento do Estado de Bem Estar Social, desenvolve-se uma visão assistencial em prol da prestação de auxílios ou amparos as pessoas com deficiência, que continuam privadas de autonomia individual e de liberdade para decidir aspectos importantes da sua vida.

Finalmente, as últimas décadas presenciaram uma verdadeira revolução no modo de compreender a deficiência. Essa mudança está atrelada ao recente desenvolvimento da teoria dos direitos humanos, cujo marco e a Declaração Universal dos Direitos 
Humanos, de 1948. Desde a apresentação do projeto original, e mesmo de iniciativas anteriores do próprio Senador Paulo Paim, o conceito de deficiência e de pessoa com deficiência tem passado por continua evolução, que encontrou seu apogeu na promulgação da Convenção sobre os Direitos da Pessoa com Deficiência, de 2009. Este documento consolida a substituição do paradigma da integração pelo da inclusão da pessoa com deficiência na sociedade. O foco, agora, não e mais eliminar ou amparar o que está supostamente errado com a pessoa, e sim corrigir o que está errado com a sociedade que as segrega por não ser capaz de derrubar as barreiras impeditivas da plena inclusão social.

Não basta alterar a legislação com base em tratados internacionais de Direitos Humanos se os pré-conceitos e pré-concepções acerca dos institutos da capacidade, autonomia, da interdição e da curatela, ainda forem entendidos e aplicados fora do contexto atual de construção identitária da pessoa com deficiência, baseada em nova epistemologia cultural e jurídica, baseada no livre desenvolvimento de sua personalidade e voltada ao pleno exercício de direitos fundamentais.

\title{
3 DO CASAMENTO DA PESSOA COM DEFICIÊNCIA
}

\author{
O artigo 23 da Carta de Nova Iorque prevê que:
}

1.Os Estados Partes tomarão medidas efetivas e apropriadas para eliminar a discriminação contra pessoas com deficiência, em todos os aspectos relativos a casamento, família, paternidade e relacionamentos, em igualdade de condições com as demais pessoas, de modo a assegurar que:

a) Seja reconhecido o direito das pessoas com deficiência, em idade de contrair matrimônio, de casar-se e estabelecer família, com base no livre e pleno consentimento dos pretendentes; [...] (BRASIL, 2009).

A efetividade do direito ao casamento da pessoa com deficiência, em exercício pleno do seu livre planejamento familiar, conforme previsto no artigo $226, \S 7^{\circ 8}$ da Constituição da República de 1988, é assegurada pelo Estatuto da Pessoa com Deficiência que expressamente revogou o inciso I do artigo 1.548 do Código Civil. Tal artigo previa que o casamento contraído pelo enfermo mental sem o necessário discernimento para os atos da vida civil era nulo. A justificativa para a revogação reside em duas frentes, dentro dos anseios da Carta de Nova Iorque: nos casos de incapacidade civil, que não levam mais em conta o fato da pessoa

\footnotetext{
${ }^{8}$ Art. 226. A família, base da sociedade, tem especial proteção do Estado. [...] $§ 7^{\circ}$ Fundado nos princípios da dignidade da pessoa humana e da paternidade responsável, o planejamento familiar é livre decisão do casal, competindo ao Estado propiciar recursos educacionais e científicos para o exercício desse direito, vedada qualquer forma coercitiva por parte de instituições oficiais ou privadas. (BRASIL, 1988).
} 
ser doente, conforme visto no tópico anterior; bem como para garantir o exercício pleno da autonomia privada, o exercício de direitos fundamentais, logo, garantir a dignidade humana.

De fato, o artigo $6^{\circ}$, inciso I do Estatuto da Pessoa com Deficiência tem previsão no sentido de que a deficiência não afeta a plena capacidade da pessoa para casar e constituir união estável: “Art. $6^{\circ} \mathrm{A}$ deficiência não afeta a plena capacidade civil da pessoa, inclusive para: I - casar-se e constituir união estável; [...].” (BRASIL, 2016). Tal previsão expressa na legislação brasileira é entendida como avanço, eis que, de um lado, visa a alterar a cultura social e jurídica de que as pessoas com deficiência, em especial a mental, não tem qualquer discernimento para o casamento; e, de outro lado, concretizam o direito de personalidade: "Para fins de casamento, portanto, há um avanço. Não podem os deficientes ser alijados da formação de família por meio do casamento ou mesmo união estável.” (SIMÃO, 2015).

O caso do casamento de R. A. O. L. e J. F. D. A., noticiado no introito (IBDFAM, 2016), onde R.A.O.L. é pessoa com deficiência mental/intelectual, demonstra, na prática, a concretização da relevância dos processos culturais e jurídicos relacionados aos direitos identitários das pessoas com deficiência para fins de execução do livre desenvolvimento de sua personalidade no Direito das famílias. Eles já vivenciavam, de fato, uma família informal há mais de 19 anos, tem um filho de 17 anos e, segundo ele, a mãe nunca esteve impossibilitada de levar uma vida normal, mas, em razão da doença, era interditada por reconhecimento jurídico de sua incapacidade absoluta no sistema anterior ao do Estatuto.

O sistema agora, prevê a plena inclusão e exercício dos atos existenciais da vida às pessoas com deficiência. Contudo, não se pode garantir direitos por um lado e abandonar a proteção por outro. Por isso, a Carta de Nova Iorque prevê no artigo 12 que:

4.Os Estados Partes assegurarão que todas as medidas relativas ao exercício da
capacidade legal incluam salvaguardas apropriadas e efetivas para prevenir abusos,
em conformidade com o direito internacional dos direitos humanos. Essas
salvaguardas assegurarão que as medidas relativas ao exercício da capacidade legal
respeitem os direitos, a vontade e as preferências da pessoa, sejam isentas de
conflito de interesses e de influência indevida, sejam proporcionais e apropriadas às
circunstâncias da pessoa, se apliquem pelo período mais curto possível e sejam
submetidas à revisão regular por uma autoridade ou órgão judiciário competente,
independente e imparcial. As salvaguardas serão proporcionais ao grau em que tais
medidas afetarem os direitos e interesses da pessoa. (BRASIL, 2009).

Logo, a própria Convenção Internacional de Direitos Humanos das pessoas com Deficiência reconhece que, na prática, a pessoa com deficiência pode ser vulnerável, determinando que o ordenamento jurídico dos países preveja medidas de proteção. Acredita- 
se que no sistema jurídico brasileiro tais medidas sejam a curatela e a tomada de decisão apoiada.

\subsection{Casamento e Curatela}

Quanto à curatela, o artigo 85 caput e o seu parágrafo primeiro ${ }^{9}$ do Estatuto da Pessoa com Deficiência trazem para o sistema uma limitação material para curatela, restringindo-se às questões patrimoniais da pessoa, de forma de os atos personalíssimos, tais como os ligados ao próprio corpo, sexualidade, matrimônio, privacidade, educação, saúde, trabalho e voto, não podem ser alcançados pela curatela (SOUZA, 2018).

Tal dicção tem o objetivo de afastar a crítica que pairava sobre o ordenamento jurídico civil anterior quando do sistema de interdição/curatela advindo desde o Código Civil de 1916 que importava em morte civil da pessoa que, uma vez interditada de forma absoluta, não era apta a prática de nenhum ato de cunho patrimonial ou pessoal; adequando-o aos ditames da Carta de Nova Iorque. De fato, as questões pessoais devem ser preservadas na maior medida do possível para o âmbito da autodeterminação da pessoa, ainda que ela seja deficiente mental ou intelectual, incluindo o casamento.

Entretanto, observa-se que na prática, a equipe multidisciplinar que avalia a deficiência pode concluir pela inexistência total de possibilidade de manifestação de vontade, tanto para atos patrimoniais quanto para atos existenciais, para somente aqueles ou para somente estes. Ademais, essa equipe pode ainda entender, da análise minuciosa da situação casuística da pessoa pela incapacidade parcial, com a delimitação de atos patrimoniais e pessoais para os quais a pessoa não tem discernimento/possibilidade de expressão de vontade. Todas essas hipóteses serão, nos termos do Estatuto da Pessoa com Deficiência, excepcionalidades. Tanto é assim, que o parágrafo segundo do seu artigo $85^{10}$ determina que o juiz deve trazer a fundamentação em sentença que, como se entende, deve se basear nos estudos perpetrados pela equipe multidisciplinar.

Recentemente, tal dispositivo teve sua constitucionalidade arguida e analisada pelo Tribunal de Justiça de Minas Gerais, na Arguição de Inconstitucionalidade n.

1.0000.17.034419-6/002:

\footnotetext{
${ }^{9}$ Art. 85. A curatela afetará tão somente os atos relacionados aos direitos de natureza patrimonial e negocial. § 10 A definição da curatela não alcança o direito ao próprio corpo, à sexualidade, ao matrimônio, à privacidade, à educação, à saúde, ao trabalho e ao voto. [...]. (BRASIL, 2016).

${ }^{10}$ [...] § 20 A curatela constitui medida extraordinária, devendo constar da sentença as razões e motivações de sua definição, preservados os interesses do curatelado. [...]. (BRASIL, 2016).

CONPEDI LAW REVIEW | QUITO - EQUADOR | v. 4 | n. 2 | p. 276 - 296 | JUL - DEZ | 2018 


\begin{abstract}
EMENTA: INCIDENTE DE INCONSTITUCIONALIDADE - DECLARAÇÃO DE INCONSTITUCIONALIDADE DOS ARTIGOS 84, CAPUT E SEU $\S 3^{\circ}$ E 85, $\S$ $1^{\circ}$ E $2^{\circ}$, AMBOS DA LEI 13.146/2015 (ESTATUTO DA PESSOA COM DEFICIÊNCIA) E ARTIGO $4^{\circ}$, INCISO III, DO CÓDIGO CIVIL - CURATELA INCAPACIDADE RELATIVA - VÍCIO INEXISTENTE - 1. A Lei 13.146/2015, no que tange ao estabelecimento da incapacidade relativa para os portadores de deficiência, está de acordo com a Convenção da ONU Sobre os Direitos da Pessoa com Deficiência, promulgada pelo Decreto ${ }^{\circ}{ }^{6} 6.949 / 2009$, com status equivalente ao de emenda constitucional, nos termos do art. $5^{\circ}, \S 3^{\circ}$, da Constituição Federal. 2. Ao estabelecer que a "curatela afetará tão somente os atos relacionados aos direitos de natureza patrimonial e negocial", o art. $85, \S 1^{\circ}$, da Lei ${ }^{\circ} 13.146 / 15$, não estipulou que o exercício do direito se daria de maneira absoluta, já que ressalvada a proporcionalidade da definição da curatela às necessidades e circunstâncias de cada caso. (MINAS GERAIS. Tribunal de Justiça do Estado. Arguição de Inconstitucionalidade $n$. 1.0000.17.034419-6/002. Relatora Desembargadora Márcia Milanez. Data de Julgamento: 14/03/2018. Disponível em: <http://www5.tjmg.jus.br/jurisprudencia〉. Acesso em: 26 mar.2018).
\end{abstract}

A conclusão da relatora foi no sentido de que a norma do artigo 85 do Estatuto, ao limitar a curatela às questões patrimoniais, não exclui a possibilidade de reconhecimento casuístico de "incapacidade para prática de determinados atos da vida civil que não se insiram na esfera patrimonial e negocial, o que deve ser verificado conforme as particularidades do caso concreto."

Logo, se a pessoa for curatelada justamente por não ter possibilidade de expressão de vontade para o casamento, não há como o mesmo ser realizado. Afinal, casamento é um negócio jurídico sui generis (RODRIGUES JÚNIOR; ALMEIDA, 2012) formando-se diante da manifestação de vontade dos nubentes, em prol do estabelecimento de uma comunhão plena de vida e formação da família matrimonial. De mais a mais, o casamento é ato personalíssimo que não admite representação ou assistência (ALMEIDA; RODRIGUES JÚNIOR, 2012, p. 97). Por essa razão o artigo 1.518 do Código Civil foi alterado pelo Estatuto da Pessoa com Deficiência, eis que previa a necessidade de autorização do curador para o casamento.

Ainda quanto à questão da atuação do curador, o Estatuto da Pessoa com Deficiência incluiu o parágrafo segundo ao artigo 1.550 do Código Civil, com a previsão de que: “[...] §2o A pessoa com deficiência mental ou intelectual em idade núbia poderá contrair matrimônio, expressando sua vontade diretamente ou por meio de seu responsável ou curador. (Incluído pela Lei $n^{\circ} 13.146$, de 2015).” (BRASIL, 2002, grifo nosso). A expressão correta é 
idade núbil ${ }^{11}$. Por outro lado, ao permitir que a vontade para o casamento da pessoa deficiente mental ou intelectual seja expressada pelo responsável ou curador gera críticas:

\begin{abstract}
Neste dispositivo andou mal o legislador. Sem falar do equívoco com a língua portuguesa (já que o termo correto seria “idade núbil"), permitiu-se que a vontade de casar seja manifestada pelo curador do deficiente. Ora, a vontade é elemento essencial ao casamento e ninguém se casa senão por vontade própria. Admitir a manifestação da vontade pelo curador carece de lógica jurídica e contraria a natureza personalíssima do casamento. A escorregada legislativa aqui foi tamanha que houve ululante contradição com o próprio art. 85 do Estatuto, que determina a atuação do curador do deficiente apenas e tão somente para os atos de natureza patrimonial e negocial (RIBEIRO, 2015).
\end{abstract}

\begin{abstract}
Novamente tem-se um problema na redação do parágrafo segundo acima transcrito: segundo o artigo 85 do Estatuto o curador do deficiente só atuará nos atos de natureza patrimonial e negocial, mas o parágrafo segundo que receberá o artigo 1550 do CC prevê que vontade de casar pode ser expressa pelo curador. Clara a contradição entre os dispositivos. A vontade é elemento essencial ao casamento e ninguém se casa senão por vontade própria. Admitir a vontade do curador como elemento suficiente para o casamento do deficiente é algo ilógico e contraria a pessoalidade do casamento, além de permitir fraudes perpetradas pelo casamento decorrente apenas da vontade do curador. O dispositivo deve ser interpretado restritivamente de acordo com a natureza personalíssima do casamento (SIMÃO, 2015).
\end{abstract}

Como já dito, se o casamento é ato personalíssimo não admite assistência e nem representação jurídica atrelada a incapacidade civil. A autorização prevista no artigo 1.517 do Código Civil para o casamento dos menores em idade núbil que ainda não completaram a maioridade civil (dezoito anos) ou a possibilidade dada pelo artigo 1.535 do Código Civil de nomeação de procurador com poderes especiais, via contrato de mandato, não afasta a característica. Afinal, como negócio jurídico personalíssimo, o casamento somente se perfaz com a exteriorização da autonomia privada da pessoa que é originada de seu discernimento para o ato (SOUZA, 2018).

Em qualquer caso, a ressalva de que a constituição de família é ato de autonomia privada que depende de manifestação de vontade só tem o condão de existir, ser válida e, portanto, produzir os efeitos de direito, se exercida com discernimento. Se este não existe ou é viciado não é possível o reconhecimento de sua existência, quiçá de sua validade e seus efeitos.

Por fim, acredita-se que ainda restam dúvidas práticas acerca do casamento, em especial da pessoa com deficiência mental, que demandarão a mudança de cultura e

${ }^{11}$ Quanto ao uso da expressão núbia, José Fernando Simão (2015) ensina que: “O adjetivo "núbia” denota o total desconhecimento da língua portuguesa. Núbia é a região da África que historicamente teve conflitos com o Egito e hoje é parte dele. O termo correto é "idade núbil", ou seja, referente às núpcias." 
experiências em prol da autonomia delas para fins de sua efetivação: quem é a pessoa responsável por aferir a capacidade para exercício da autonomia privada? É o oficial da serventia extrajudicial? Se ele tiver dúvida deve suscitá-la ao juízo? Seria o juízo da vara de registros públicos competente para determinar ou confirmar a capacidade para o casamento, ou seja, o discernimento, a possibilidade de manifestação de vontade para casar?

\subsection{Casamento e Tomada de Decisão Apoiada}

Quanto à tomada de decisão apoiada, trata-se de apoio casuístico, na hipótese de diminuição da possibilidade de expressão de vontade para fins de exercício da autonomia privada, sem reconhecimento de incapacidade, logo não importa em curatela, ainda que no sistema pós Estatuto da Pessoa com Deficiência esta também seja casuística (SOUZA, 2016). A previsão e o procedimento da tomada de decisão apoiada estão no artigo 1.783-A do Código Civil, que foi incluído pelo Estatuto da Pessoa com Deficiência.

Os apoiadores não são curadores, são pessoas de confiança da pessoa com deficiência e a auxiliarão para tomar certa decisão, seja de cunho patrimonial, seja de cunho personalíssimo, como o casamento. Enquanto o curador assiste ou representa o curatelado assim considerado incapaz, o apoiador, especificamente para um ato ou conjunto de atos determinados, atua mantida a capacidade da pessoa apoiada.

Logo, a tomada de decisão apoiada é possível para o exercício da autonomia privada no casamento em mudança cultural e jurídica, executando os ditames da Carta de Nova Iorque.

\subsection{Anulabilidade e anulação de casamento de Pessoas com Deficiência}

O casamento da pessoa incapaz de consentir ou manifestar, de modo inequívoco, o consentimento era causa de nulidade. Entretanto, o artigo 1.550, inciso IV do Código Civil, que trata da anulabilidade do casamento, teve sua redação alterada pelo Estatuto da Pessoa com Deficiência: “Assim, pode-se concluir que o casamento do deficiente que for incapaz de consentir ou manifestar de modo inequívoco o seu consentimento pode ser anulável, mas não nulo.” (RIBEIRO, 2015). 
Ainda quanto às questões de anulação do casamento, o Estatuto da Pessoa com Deficiência alterou o artigo 1.557 do Código Civil que trata do erro essencial quando a pessoa do outro cônjuge. Sobre o tema doutrina Flávio Tartuce (2015):

\begin{abstract}
Como decorrência natural da possibilidade de a pessoa com deficiência mental ou intelectual se casar, foram alterados dois incisos do art. 1.557, dispositivo que consagra as hipóteses de anulação do casamento por erro essencial quanto à pessoa. O seu inciso III passou a ter uma ressalva, eis que é anulável o casamento por erro no caso de ignorância, anterior ao casamento, de defeito físico irremediável que não caracterize deficiência ou de moléstia grave e transmissível, por contágio ou por herança, capaz de pôr em risco a saúde do outro cônjuge ou de sua descendência (destacamos a inovação). Em continuidade, foi revogado o antigo inciso IV do art. 1.557 do CC/2002 que possibilitava a anulação do casamento em caso de desconhecimento de doença mental grave, o que era tido como ato distante da solidariedade ("a ignorância, anterior ao casamento, de doença mental grave que, por sua natureza, torne insuportável a vida em comum ao cônjuge enganado").
\end{abstract}

Considerando as alterações, se um cônjuge entender que a deficiência do outro, ainda que não conhecida antes do casamento, é causa para tornar insuportável a vida em comum, não poderá pleitear a anulação do casamento em razão de erro essencial, cabendo a via do divórcio para extinção da sociedade e do vínculo conjugal (SOUZA, 2018).

Os casamentos realizados antes da entrada em vigor do Estatuto da Pessoa com Deficiência e que se enquadrassem no disposto no artigo 1.548, I do Código Civil, hoje revogado pelo Estatuto, continuarão nulos, pois o sistema de Direito Civil costuma aplicar a lei do tempo do ato, ex vi do artigo 2.039 do Código Civil. Nesse sentido:

Assim, caso tenha ocorrido um casamento de uma pessoa deficiente, sem discernimento para os atos da vida civil, antes da vigência do Estatuto, este casamento nasceu nulo por afronta ao inciso I do artigo 1.548 do CC e não se torna "válido" pela alteração legislativa. Prevalece, pois, a lei do momento da celebração do casamento. Destarte, os enfermos mentais sem o discernimento para os atos da vida civil estarão aptos ao matrimônio a partir da entrada em vigor do Estatuto da Pessoa com Deficiência, em janeiro de 2016 (RIBEIRO, 2015).

\title{
4 CONSIDERAÇÕES FINAIS
}

A inclusão da pessoa com deficiência, em especial quanto ao exercício de direitos existenciais e a extinção da "morte civil" do ordenamento brasileiro são realidades trazidas pelo Estatuto da Pessoa com Deficiência. Afinal, à luz dos anseios da Carta de Nova Iorque, a deficiência, por si só, não é causa de incapacidade e a curatela não pode incidir sobre questões envolvendo o Direito de Personalidade dos deficientes. 
Assim, o casamento da pessoa com deficiência é permitido pelo Direito brasileiro, como exercício pleno do livre desenvolvimento de sua personalidade. Entretanto, exige-se ato de autonomia privada que, por sua vez, depende da autodeterminação, ou seja, do discernimento, possibilidade de expressão de vontade da pessoa.

O Direito deve buscar concretizar Direitos Humanos, de forma a garantir a correspondência entre os contextos de vida real e a normatividade, agregando as evoluções dos movimentos sociais e os processos culturais relacionados aos direitos identitários e de família, no caso específico das pessoas com deficiência.

Não basta alterar a legislação com base em tratados internacionais de Direitos Humanos se os pré-conceitos e preconcepções acerca dos institutos da capacidade, autonomia, da interdição e da curatela, ainda forem entendidos e aplicados fora do contexto atual de construção identitária da pessoa com deficiência, baseada em nova epistemologia cultural e jurídica, baseada no livre desenvolvimento de sua personalidade e voltada ao pleno exercício de direitos fundamentais.

\section{REFERÊNCIAS}

ALMEIDA, Renata Barbosa de; RODRIGUES JUNIOR, Walsir Edson. Direito Civil: Famílias. 2.ed. São Paulo: Atlas, 2012. 588p.

AMARAL, Francisco. Direito civil: introdução. 6.ed. Rio de Janeiro: Renovar, 2006. 662p.

BRASIL. Constituição da República Federativa do Brasil de 1988. Disponível em: <http://www.planalto.gov.br/ccivil_03/constituicao/constituicaocompilado.htm>. Acesso em: 15 jul. 2014.

BRASIL. Decreto n. 3.298, de 20 de dezembro 1999. Regulamenta a Lei no 7.853, de 24 de outubro de 1989, dispõe sobre a Política Nacional para a Integração da Pessoa Portadora de Deficiência, consolida as normas de proteção, e dá outras providências. Disponível em: <http://www.planalto.gov.br/ccivil_03/decreto/d3298.htm>. Acesso em: 02 Mai. 2018.

BRASIL. Decreto n. 6.949, de 25 de agosto de 2009. Promulga a Convenção Internacional sobre os Direitos das Pessoas com Deficiência e seu Protocolo Facultativo, assinados em Nova York, em 30 de marco de 2007. Disponível em: <http://www.planalto.gov.br/ccivil_03/_ato2007-2010/2009/decreto/d6949.htm>. Acesso em: 30 Jan. 2015. 
BRASIL. Lei n. 3.071, de $1^{\circ}$ de janeiro de 1916. Código Civil dos Estados Unidos do Brasil. Disponível em: <http://www.planalto.gov.br/ccivil_03/leis/13071.htm>. Acesso em: 25 Jun. 2018.

BRASIL. Lei n. 5.869, de 11 de janeiro de 1973. Institui o Código de Processo Civil. Disponível em: <http://www.planalto.gov.br/ccivil_03/leis/15869.htm>. Acesso em: 14 Ago. 2014.

BRASIL. Lei n. 10.406, de 10 de janeiro de 2002. Institui o Código Civil. Disponível em: <http://www.planalto.gov.br/ccivil_03/LEIS/2002/L10406.htm>. Acesso em: 25 Jun. 2018.

BRASIL. Lei n. 13.146, de 6 de julho de 2015a. Institui a Lei Brasileira de Inclusão da Pessoa com Deficiência (Estatuto da Pessoa com Deficiência). Disponível em: <http://www.planalto.gov.br/ccivil_03/_Ato2015- 2018/2015/Lei/L13146.htm>. Acesso em: 14 Ago. 2015.

BRASIL. Lei n. 13.105, de 16 de marco de 2015b. Código de Processo Civil. Disponível em: <http://www.planalto.gov.br/ccivil_03/_Ato2015-2018/2015/Lei/L13105.htm>. Acesso em: 05 de Abr. 2015.

FARIA, Romário. Parecer n. 266, de 2015. Substitutivo da Câmara dos Deputados n. 4, de 2015, ao Projeto de Lei do Senado n. 6, de 2003 (Projeto de Lei n. 7.699, de 2006, na Câmara dos Deputados), do Senador PAULO PAIM, que institui o Estatuto da Pessoa com Deficiência - Lei Brasileira da Inclusão. Disponível em: $<$ http://www.senado.leg.br/atividade/rotinas/ materia/getDocumento.asp?t=167218>. Acesso em: 22 Dez. 2015.

FARIAS, Cristiano Chaves de; ROSENVALD, Nelson. Curso de Direito Civil: Parte Geral e LINDB. 10.ed. Salvador: JusPodvm, 2012. 856p.

FARIAS, Cristiano Chaves de; ROSENVALD, Nelson. Direito Civil: Teoria Geral. 8.ed. Rio de Janeiro: Lumen Juris, 2009. 776p.

FIUZA, Cesar. Direito Civil: curso completo. 14. ed. Belo Horizonte: Del Rey, 2010. 1123p.

IBDFAM. Cartório paulista sai na frente e realiza casamento inédito de pessoa com deficiência, depois da Lei Brasileira de Inclusão. Publicado em 02 Mar. 2018. Disponível em:

$<$ http://ibdfam.org.br/noticias/5919/Cart\%C3\%B3rio+paulista+sai+na+frente+e+realiza+o+pr imeiro+casamento+de+pessoa+com+defici\%C3\%AAncia\%2C+depois+da+Lei+Brasileira+de +Inclus\%C3\% A3o+>. Acesso em: 30 Jun. 2018.

LOBO, Paulo Luiz Netto. Com avanços legais, pessoas com deficiência mental não são mais incapazes. Revista Consultor Jurídico. 16 Ago. 2015. Disponível em: $<$ http://www.conjur.com.br/2015ago16/processofamiliaravancospessoasdeficienciamentalnao saoincapazes>. Acesso em: 22 Dez. 2015. 
MINAS GERAIS. Tribunal de Justiça do Estado. Apelação Cível 1.0427.13.001117-9/001. Relator Des.Wilson Benevides. Órgão Julgador: $7^{\text {a }}$ Câmara Cível. Data de Julgamento: 25/04/2017. Disponível em: 〈www.tjmg.jus.br〉. Acesso em: 10 Out. 2017.

MINAS GERAIS. Tribunal de Justiça do Estado. Arguição de Inconstitucionalidade n. 1.0000.17.034419-6/002. Relatora Desembargadora Márcia Milanez. Data de Julgamento: 14/03/2018. Disponível em: <http://www5.tjmg.jus.br/jurisprudencia>. Acesso em: 26 mar.2018

RIBEIRO, Moacyr Petrocelli de Avila. Estatuto da Pessoa com Deficiência: a revisão da teoria das incapacidades e os reflexos jurídicos na ótica do notário e do registrador. Publicado em: $26 \quad$ Ago. $2015 . \quad$ Disponível <http://www.notariado.org.br/index.php?pG=X19leGliZV9ub3RpY2lhcw==\&in=NjIy$\mathrm{MA}==>$. Acesso em: 22 Dez. 2015.

ROSEnlvad, Nelson. Conheça o Estatuto da Pessoa com Deficiência. 24 Ago. 2015. Disponível em: <http://www.nelsonrosenvald.info/\#!ConheçaoEstatutodaPessoacomDeficiência/ c21xn/55dd00010cf2c4072861d98d>. Acesso em: 22 Dez. 2015.

SÁ, Maria de Fátima Freire de; MOUREIRA, Diogo Luna. A capacidade dos incapazes: saúde mental e um releitura da teoria das incapacidades no direito privado. Rio de Janeiro: Lumen Juris, 2011. 190p.

SA, Maria de Fatima Freire de; NAVES, Bruno Torquato de Oliveira. Manual de Biodireito. 3. ed. Belo Horizonte: Del Rey, 2015. 432p.

SIMÃO, Jose Fernando. Estatuto da Pessoa com Deficiência causa perplexidade (Parte 2). Revista Consultor Jurídico. 7 Ago. 2015. Disponível em: <http://www.conjur.com.br/2015ago07/josesimaoestatutopessoadeficienciatrazmudancas>. Acesso em: 22 Dez. 2015.

SOUZA, Iara Antunes. Estatuto da Pessoa com Deficiência: curatela e saúde mental. 1. ed. Belo Horizonte: D'Plácido Editora, 2016. 464p.

SOUZA, Iara Antunes de Souza. Reflexões sobre os impactos do Estatuto da Pessoa com Deficiência no Direitos das Famílias: curatela e casamento. In.: PEREIRA, Fábio Queiroz; MORAIS, Luísa Cristina de Carvalho; LARA, Mariana Alves (Orgs.). A teoria das incapacidades e o estatuto da pessoa com deficiência. 2.ed. Belo Horizonte: Ed. D’Plácido, 2018. p.203-217.

STANCIOLI, Brunello Souza. Relação jurídica médico-paciente. Belo Horizonte: Del Rey, 2004. 144p.

TARTUCE, Flavio. Alterações do Código Civil pela lei 13.146/2015 (Estatuto da Pessoa com Deficiência). Repercussões para o Direito de Família e Confrontações com o Novo CPC. Parte I. Migalhas. Família e Sucessões. 29 Jul. 2015. Disponível em: <http://www.migalhas.com.br/FamiliaeSucessoes/104,- 
MI224217,21048Alteracoes+do+Codigo+Civil+pela+lei+131462015+Estatuto+ da+Pessoa+com>. Acesso em: 22 Dez. 2015. 